\title{
Advocate Notepad: An Android Application
}

\author{
Sonal Gupta \\ Assistant Professor \\ ABES Engineering College \\ Ghaziabad (UP), India
}

\author{
Aayushi Gupta \\ Student \\ ABES Engineering College \\ Ghaziabad (UP), India
}

\author{
Aayush Mittal \\ Student \\ ABES Engineering College \\ Ghaziabad (UP), India
}

\begin{abstract}
Smartphones are steadily gaining popularitywith an estimated 1.6 billion mobile device users by 2013. With the advancement of technology, creation of new android based application plays an important role in making common man life easy and smart.A number of Android applications are developing in the market by a rapid rate. Managing common man task in various fields like entertainment, lifestyle, business, social, games etc. with these applications is today's demand.

Motivated with this, a free Android app named Advocate Notepad is proposed and developed in this paper for advocates to help them in maintaining the records of the cases on day to day basis with the details of the nature of the proceedings conducted on a particular day. Common man can use this App to know and learn about basic Laws that help common people to get rid of being exploited by one way or another.This app helps user in knowing basic Laws like air pollution, water pollution, waste management, chemical safety, forest resources under environment law. Time to time Reminders to advocates about their cases is an additional feature incorporated in the app.
\end{abstract}

\section{Keywords}

Android SDK, Android Application, Modules

\section{INTRODUCTION}

OnSeptember 23 2001, Google developed a mobile operating system called Android. An Android app is a software application running on the Android platform. Android Applications are written primarily in java programming language using the Android Software development kit (SDK) which includes a comprehensive set of development tools. By July 2013, the Google Play store consists over one million Android applications published, and over 50 billion applications downloaded worldwide. With the passage of time, various versions of android like Froyo, Gingerbread, Ice Cream Sandwich, JellyBean, KitKat, Lollipop and the latest one is Lollipop MR 1 are introduced in the market with new one overcoming the bugs and shortcomings of previous version. . There were about 67 million smartphones in India in 2013 out of which, nearly $90 \%$ are android based.Thus the knowledge of "legal education" via an Android application will help a lot to solve the general problems as it is a widely used technology at present. Law is a system of rules that helps to manage politics, economics and society in a number of ways. Our constitution has provided certain fundamental Rights for every citizen as well as for every person and unawareness of these fundamental rights result to their violation. Thus Basic and fundamental knowledge is a must for these common people so that they may not get exploited and their knowledge of the laws helps them to take benefit of their rights.

Thus basic knowledge of certain laws and regulations is must for a person even though it does not relate to legal field. Let's take an example: Some situation may arise like breaking traffic rule in hurry or by mistake that can result you to pay unnecessary Money to the traffic police as bribe; but the person's accurate knowledge or availability to these laws using this app can help him to pay or take exact decision as per the Law and not what is wrong. Usually a common man has to pay certain amount to the Lawyer to whom he may concern for small issues like Dowry, environmental issues, family issues etc. In such situation, the availability of legal informationas first-aid will help the common man in protecting his fundamental rights.

Another aspect of Legal World relates with Advocates as they are an important part of it. Usually advocate hire attendant for maintaining their regular case details and past history, but maintaining a manual diary may not be as effective with today's advance technologies.Thus, incorporation of technology such as android app in this field can be of great use to advocate as well as common men.It will also be more secure and speedy.

Therefore, an android application is proposed in this paper to incorporate technology in the field of Law for advocates and common man. This android application will play a key role in providing a simple, systematic and speedier life to the advocates. This will help the advocates in raising their standards of working and in providing a better service to their clients while saving their time and resources.The proposed app will provide all information regarding day-to-day cases, client's personal information, completed and ongoing cases, basic Laws and Rights at their fingertips anytime, anywhere. Searching, notifications, setting reminder are other features that will enhance the importance of this app for advocates. The objective of the app also focus in resolving the problem of violation and exploitation of common man fundamental rights by providing them the basic knowledge of Laws and Rights such as penalties or punishments associated with exploitation of rules and regulations.

The rest of the paper is organized as follows. In Section II, we will present the study of related work done regarding the incorporation of technology in the field of Law.In Section III, we propose the design of the proposed app. In Section IV, we discuss the implementation details regarding the development of app.In Section V, we present the results of the developed app. In Section VI, we conclude the paper.

\section{RELATED WORK}

In this section, we present the existing websites and android applications that aim to fulfill the same criteria as ours but are lacking behind due to some reasons. Some of them are discussed below.

\subsection{Manual Diary}

The concept of maintaining a Manual Diaryis oneof the earliest methodsfor storageand retrieval ata later date by the advocates and is now replaced by other methods due to the various shortcomings like absence of alert system, lack of privacy, difficulty in updation, wastage of time and paper, limited flexibility, high maintainance etc. 


\subsection{Web-based Applications}

These applications uses a website as an interface between user and application that allow user to access anytime, anywhere using browser and internet facility.Some of these are discussed below

\subsubsection{Thevakeel.com}

This site is used to maintain the details to be managed by Advocates about their different Cases, Detail of their Clients, Search various Cases via various ways etc.The major con of this site is its non-availability on Smart-phones, hosting cost, Large overhead to manage bulk of data, portability and high maintainance, internet connection. As Android App can provide these facilities with more without Laptop or PC usage, it will be better to port such applications on smartphones [1].

\subsubsection{Indian Kanoon}

It is aSearch Engine for different Rights and Law by various keywords like acts related to Women, Property Act, Acts defining traffic rules, Acts against Exploitation of Children, Domestic Violence Act etc.But the understanding of various sections and their further subdivision may be difficult for common people.So a direct source of information for common Laws and rights seems better [2].

\subsubsection{Advocate-Diary}

This tool is designed to provide an electronic assistant to the advocates to manage their case and client's information, to maintain their schedule and fees details etc.

The availability of all case details at a place enhance this website, but the major con is its trial period of 15 day onlyafter whichcharges are imposed for further usage. Also, it does not provide features like notifications, reminder, information regarding laws and rights[3].

\subsection{Android Applications}

Since the usage of smart phones is more common than computers today and they offer many features in a portable and simpler way,Android applications are much in trend.Some of the android based applications for advocates are given below:

\subsubsection{Advocate Diary Case Mgt.Free}

This app incorporate certain featres like schedule reminder on email either weekly or monthly, manage cases, offline application functionality, multiple website support etc. This android app involves Pro version charges- 499/- for One year and includes services like database collection. The cost charged for the app to get installed is a major drawback of it along with the non-availability of rights information for common man[4].

\subsubsection{Advocates' Diary}

This android application was Created in July 23,2012 for the advocates to alter their manual diary by providing fast and simple way for its maintainance.Being one of the earlier android app for the use of advocates, the maintain drawback of it is its installation charges of Rs.300 per year [5].

\subsubsection{The Advocate}

This app gives us access to up-to-date local news of various fields like Law, sports, entertainment etc. This app maintains the up-to-the-minute local news coverage, in-depth coverage of SU, LSU, and Saints etc. but the major drawback of this app is that it does not allow advocates to maintain their case and client details as well as lack behind in keeping updated Laws and Rights [7].

According to the market survey, the above mentioned are some of the web-based and android based tools developed for advocates, each having pons andcons that make their usage limited and inappropriate. To overcome the shortcomings of these existing work and providing advocates much more ease, we developed an Android Application which will be available at Google Play Store Free of cost and also provides high Quality Service to the Advocates as well as easy understandability to the Common man.

\section{PROPOSED DESIGN}

An Android app named ADVOCATE NOTEPAD is developed and presented in this paper for advocates to help them in maintaining the records of the cases on day to day basis with the details of the nature of the proceedings conducted on a particular day. The life of an Advocate revolves and guided by his/her Diary of cases and is virtually handicapped without it. Using this app, they can have all the information they need about all the cases of the clients, at their fingertips, which they can use anytime of the day or night and at any place. This app helps them to manage and coordinate their cases, which will enhance their productivity and earning. Time to time Reminders to advocates about their cases is an additional feature incorporated in the app.

The proposed app is represented with the help of an use case diagram as shown in Fig.1 that represents advocate and user that can use the app and access its features at their ease.The app will be available at google play store free of cost.Every person who installed the app needs to sign-in himself at first step.Once sign-in, the advocate will have access to the app with the entire database maintained personally on his phone.Different features are available to the Advocate like add a case, view all cases, Search a case (by a keyword), Access to Laws and Rights, get notification for today's case etc.

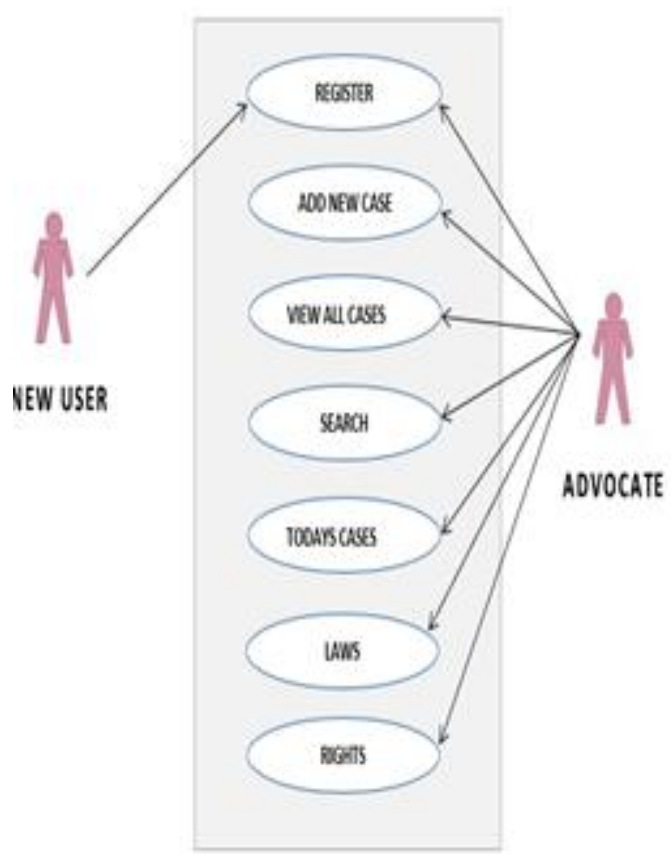

Fig 1: Use Case diagram 
The project aims to present an organized, secure, feasible and efficient way of maintaining diary of lawyer digitally. The app will ease the maintenance of case records and all related information with the motive of transforming the present day paper-work based storage to full-fledged digital storage system. The system will be providing seamless applications capable of handling large-scale records.

\section{MODULAR DIVISION OF APPLICATION}

The project is basically divided into following modules: Registration Module, Add A Case Module, All Cases Module, Search A Case Module, Today's Case Module, Laws Module, Rights Module, Admin Portal Module, Settings Module. This section describes the basic functioning idea of each module.

Registration- A new user can register by filling registration form by filling its email-id and phone number a two mandatory fields that creates an account on Advocate Notepad to access its features.

Add a Case Module- An advocate can add new case details in the app such as Name of Client, Mobile No. , Email, Address, Case Name, Case Details, Case Category, Date.

All Cases Module- The all cases module enables advocate to look onto his various cases and its history. It provide all the cases added by each advocate.

Search a Case Module- An advocate can use this module to search and get entire details for the case which have been added by him in the past, so its time get saved.

Today's Case- This module enables its advocate to have a look onto the cases which are going to take place today and alsogets a notification as a reminder to him.

Laws and right- This module provides information about the laws made in the constitution of India. The bad luck is people of India are not aware of Indian laws and rights available to them and are thus bribed, looted at several places. This app tries to ease this task by making available general basic law and rights category wise.

Admin Portal Module- This module gives rights to the administrator of the system to log in and can add new features to the app as well as update the laws and rights module.

Fig, 2 shows the interaction of the android app interface i.e the client side with the database and server with the help of sequence diagram. The vertical line indicates the objects and horizontal line indicates the message exchange to access the data and interaction between the client and server.

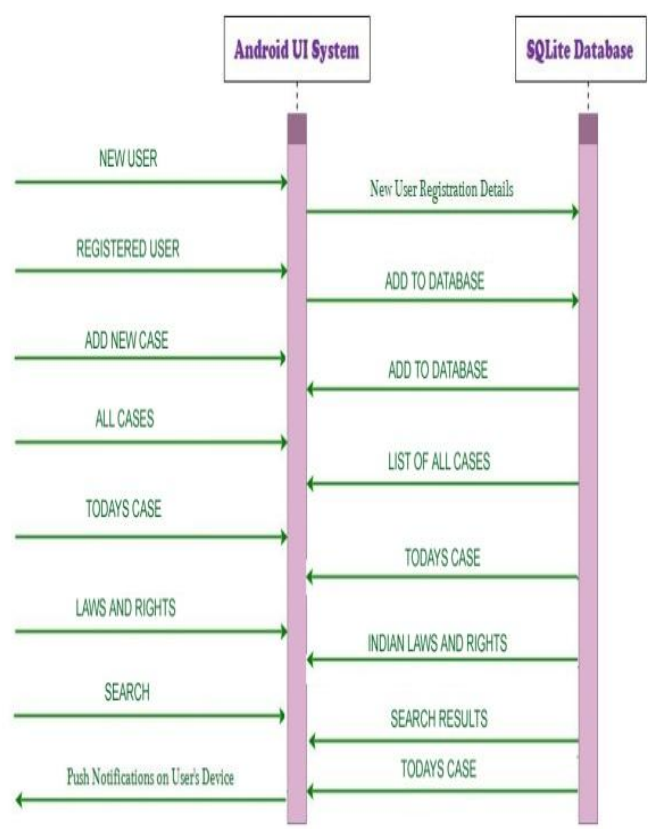

Fig 2: Sequence Diagram

\section{RESULTS}

To evaluate the functioning of each mentioned module,the results of each working module is snapped and shown from fig. 3 to fig. 7 isshown as:

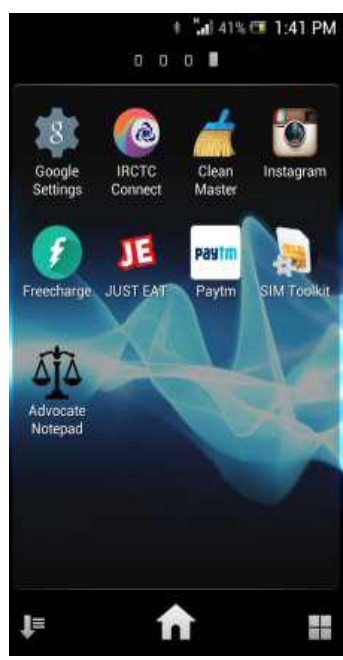

Fig 3: Application Icon

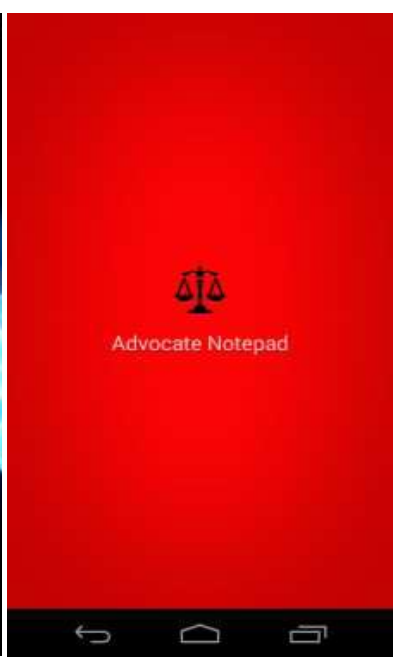

Fig 4: Loading Page 

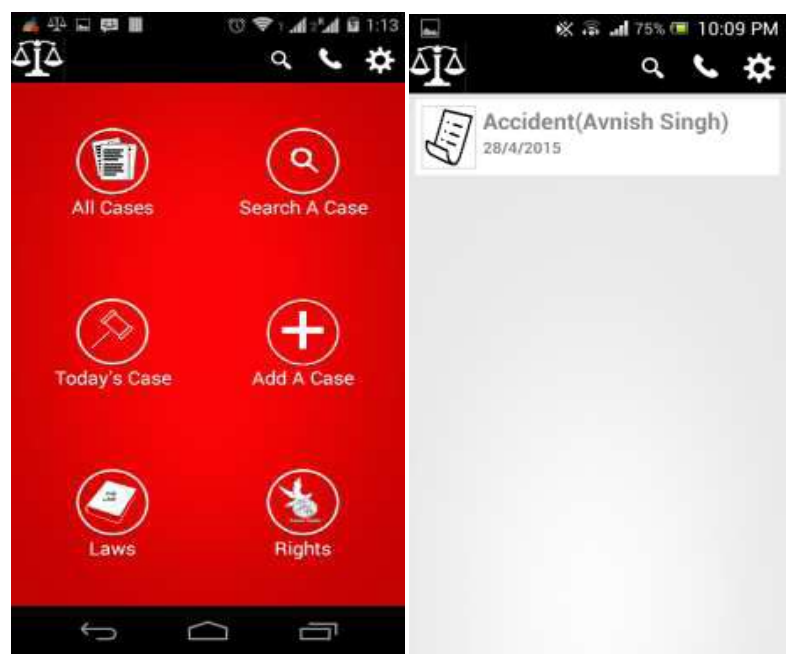

Fig 5: Various Modules

Fig 6: All Case Details

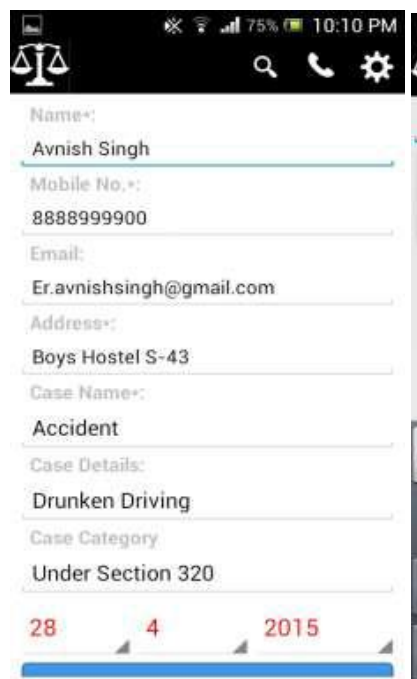

Fig 7: Case Details

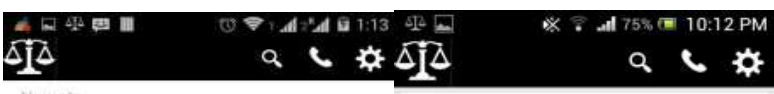

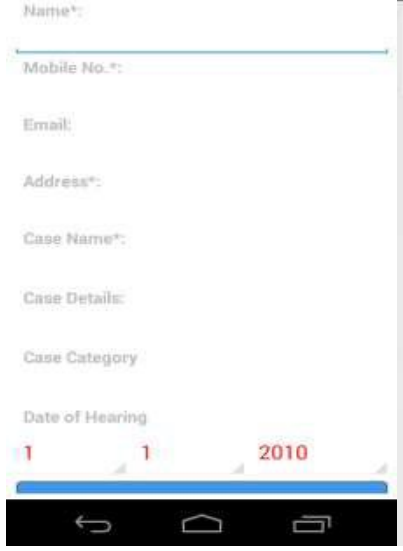

Fig 9: Add a Case

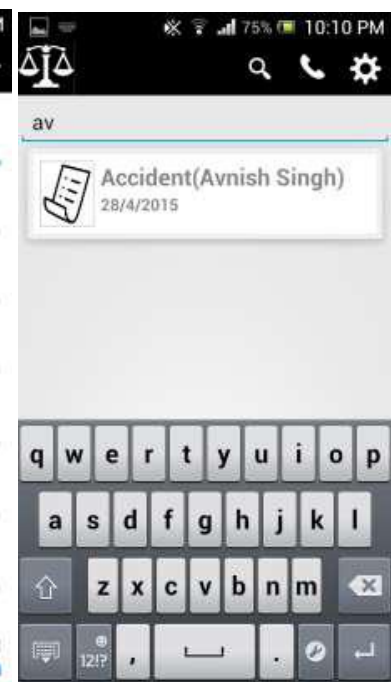

Fig 8: Searching a Case $\approx$ Hit And Run(Bhuvnesh Tejwani)
29/4/2015

$$
29 / 4 / 2015
$$

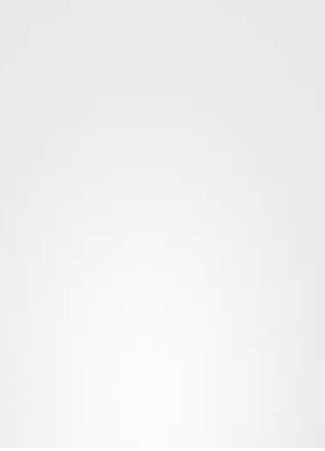

Fig 10: Today's Case
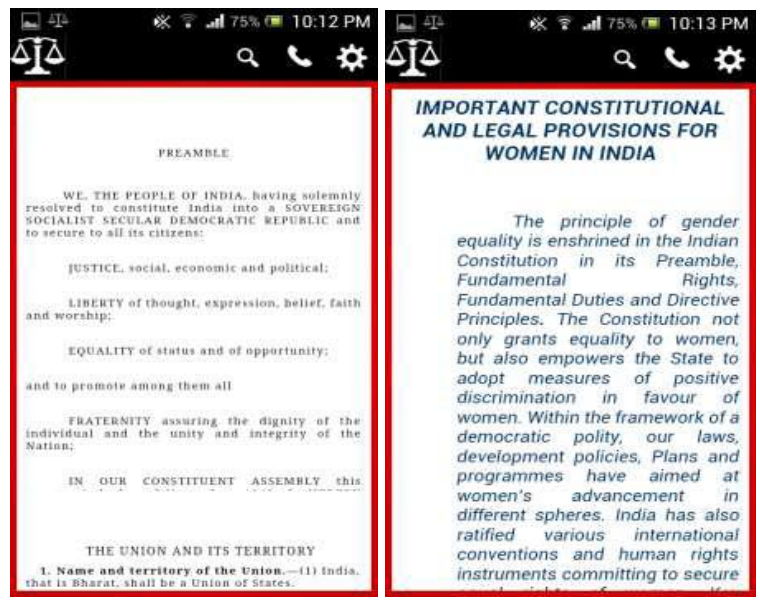

Fig 11: Law Details

Fig 12: Various Rights
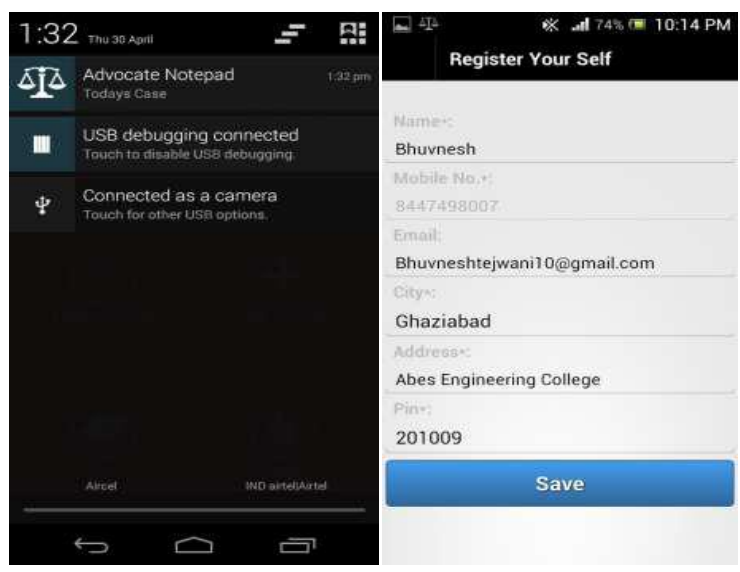

Fig13: Today's Notification Fig 14: Setting Module

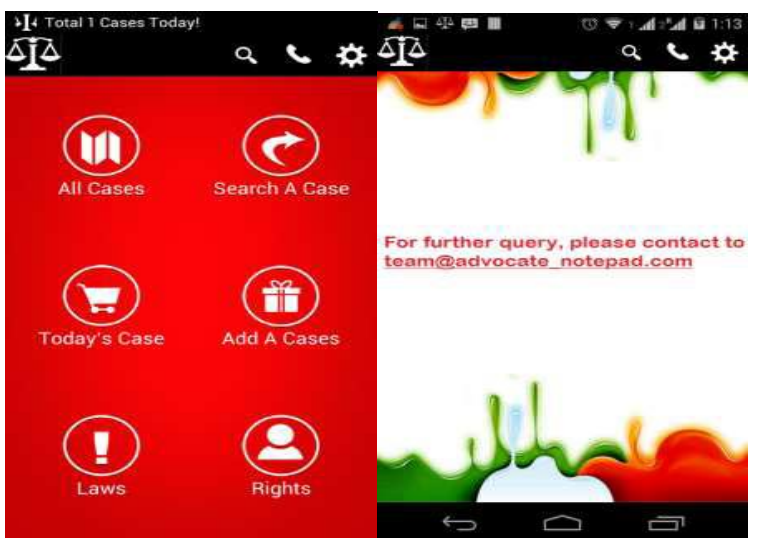

Fig 15: Notification

Fig 16: Contact Us

We believe the proposed application not only facilitates advocates in maintaining their day-to-day records but also aims at providing them a simple, speedier and systematic life. Even though it can also help the advocates and common people to gain the knowledge of various rights, Laws etc much quickly and in a simple way. In this aspect, it is important to point out that adopting this application is more beneficial for advocates than any other means of maintaining their records safely.Hence, our goal of developing an android application for advocates and common people is a useful tool for them. 


\section{CONCLUSION AND FUTURE WORK}

We would appreciate further discussions and implementations in the project in the future, as a study must never stop. We have done much to make the application work good and look better and we tried to give our best in fulfilling our duty to grow this application as much as we were able to, in the given period of time. We would appreciate anyone's interest in growing this particular work further if the person wishes to. Some modules in the project like the Push Notification module, server implementation, etc. are still under implementation. We would like to add user panel, some ebooks, GPS settings etc. are some other functions that need consideration in the future. Other functions of the like chat between advocate and client, etc. also need to be considered in the fore-coming future. At last, the developers would appreciate any further studies and thoughts that can be added to the android developer, if the reader wishes to.

\section{REFERENCES}

[1] Thevakeel.com[Online]Available FTP:http://www.thevakeel.com

[2] IndianKanoon[Online]AvailableFTP:https://www.google .co.in/search?q=Indian+Kanoon\&gws_rd=cr,ssl\&ei=jUhl VfeDItfmuQSusYDQCg

[3] Advocate-Diary[Online] Available FTP:http://advocatediary.com/

[4] Advocate Diary Case Mgt. CaseDiary [Online] Available FTP:https://play.google.com/store/apps/details?id=com.a cm_honey\&hl=en

[5] Silberman, M. 1996. Active Learning: 101 Strategies To Teach Any Subject, Prentice-Hall.

[6] TheAdvocate[Online] Available FTPhttps://play.google.com/store/apps/details?id=com.sp reedinc.providers.capitalcitypress.batonrougeadvocate\&h l=en 